\title{
Análise das estratégias de marketing adotadas pela EMBRATUR no portal Braziltour.com"
}

\author{
Analysis of the marketing strategies adopted by EMBRATUR in the portal \\ Braziltour.com
}

\author{
Cynthia Harumy Watanabe Corrêa (CORRÊA, C. H. W. $)^{1}$
}

\begin{abstract}
RESUMO - A adoção das Tecnologias da Informação e da Comunicação e da internet é importante para a promoção de destinos turísticos em nível global. No entanto, para um destino turístico se distinguir de tantos outros ao alcance do público via internet, torna-se essencial o desenvolvimento de projetos de Marketing eletrônico. Nesse sentido, apresenta-se um estudo com o objetivo de investigar as estratégias de Marketing eletrônico do Brasil como destino turístico internacional adotadas pelo Instituto Brasileiro de Turismo (EMBRATUR) para verificar se atendem as demandas do novo turista. Trata-se de uma pesquisa exploratória e de caráter qualitativo baseada em revisão de literatura e na análise do portal www.braziltour.com, conforme o método aplicado ao estudo da promoção de destinos turísticos via Web de Díaz Luque (2005) com foco em quatro aspectos: conteúdo informativo, capacidade de comercialização e distribuição, canais de comunicação interativos usados e versões do portal em idiomas estrangeiros. Conclui-se que no portal há informações relevantes sobre o país, embora o conteúdo não esteja bem distribuído; aspectos naturais e culturais predominam como imagens da marca Brasil; há um uso intenso de recursos da Web 2.0 para interagir com o público estrangeiro e versões do portal em idiomas diversos.
\end{abstract}

Palavras-chave: Marketing eletrônico; Destino turístico; Brasil; Promoção.

ABSTRACT - The adoption of Information and Communications Technologies and the Internet is important for the promotion of tourism destinations around the world. However, for a tourist destination be distinguished from others available to the public on the internet, it is essential the development of Webmarketing projects. So, the purpose of this study was to investigate Brazilian Institute of Tourism (EMBRATUR) Webmarketing strategies, positioning Brazil as an international tourism destination, and verify if these strategies correspond to the new tourists' demand. Based on a literature review and exploratory qualitative research, it was analyzed the Website www.braziltour.com. The method applied was the promotion of tourism destinations on the Web, created by Díaz Luque (2005), which has considered four aspects: information content, commercialization and distribution capacity, interactive communication channels and versions of Website in foreign languages. It was concluded that the Website presents relevant information about the country although the content should be better organized; nature and culture aspects define the Brazil brand; there is an intensive use of the Web 2.0 resources to interact with the foreigners and versions of the Website in several languages.

Key words: Webmarketing; Tourism Destination; Brazil; Promotion.

\footnotetext{
* A versão preliminar deste trabalho foi apresentada no $1^{\circ}$ Congresso Mundial de Comunicação IberoAmericana, realizado de 1 a 4 de agosto de 2011, em São Paulo.

${ }^{1}$ Graduação em Comunicação Social (Bacharelado) pela Universidade Federal do Pará (UFPA). Mestre em Comunicação e Informação pela Universidade Federal do Rio Grande do Sul (UFRGS). Doutorado em Comunicação Social pela Pontifícia Universidade Católica do Rio Grande do Sul (PUCRS). Ocupação profissional: Professora do Curso de Lazer e Turismo da Escola de Artes, Ciências e Humanidades da Universidade de São Paulo. Endereço postal: Rua Arlindo Bettio, 1000 (Ermelino Matarazzo). CEP: 03828-000 - São Paulo - SP (Brasil). Telefone: 11 9294-2612. E-mail: cynthiacorrea@ usp.br
} 


\section{INTRODUÇÃO}

A internet como mídia de fluxo intenso e detentora de uma estrutura informacional apropriada às práticas de negócios oferece inúmeras possibilidades para as empresas, sobretudo às vinculadas ao turismo que, devido à característica intangível de seu produto, dependem de canais de comunicação eficientes para atrair clientes. Conforme a Organização Mundial do Turismo - OMT (2003), o comércio eletrônico proporciona novas e gratificantes oportunidades, sendo a adoção das Tecnologias da Informação e da Comunicação (TIC), em especial a internet, imprescindível para a comercialização, distribuição, promoção e coordenação do setor.

A crescente associação do trade turístico com as TIC deu origem à expressão eTourism, que se refere à digitalização de todos os processos e cadeias de valor do turismo (BUHALIS, 2003); ao envolver funções como eCommerce (Comércio eletrônico), eMarketing (Marketing eletrônico), eFinance (Finanças eletrônicas) e eManagement (Gerência eletrônica). Nesse sentido, as TIC são vistas como instrumentos competitivos para a promoção de destinos turísticos, todavia, é necessário haver um investimento em planos de eMarketing para consolidar a marca de uma destinação. Entre as estratégias adotadas para a promoção turística na internet, destacase a criação de Web sites e portais de promoção de destinos, cujo objetivo principal é a divulgação de conteúdos e recursos visando satisfazer às necessidades dos turistas, a fim de que possam se deslocar ao destino (DIAZ LUQUE; GUEVARA; ANTON, 2006).

Também para as organizações promotoras de marketing de destinos, a rede internet representa o primeiro recurso para estabelecer comunicação com os potenciais turistas na atualidade (BUHALIS, 2000; GRETZEL et al., 2006). Entretanto, quando se pensa na situação do Brasil com a proximidade dos megaeventos esportivos internacionais (Copa do Mundo de Futebol de 2014 e Jogos Olímpicos de 2016), manifesta-se uma preocupação com o planejamento do Instituto Brasileiro de Turismo (EMBRATUR) para promover a imagem e a marca do país via internet. Nesse caso, o presente estudo foi desenvolvido com o objetivo de investigar as estratégias de eMarketing do Brasil como destino turístico internacional, a partir das ações realizadas no portal "Brazil tour", de modo a examinar se essas estratégias atendem as demandas do novo turista, cada vez mais sofisticado, exigente e independente (BUHALIS; LAW, 2008). 
Para tanto, realizou-se um estudo exploratório e de caráter qualitativo baseado em revisão de literatura e na análise do portal www.braziltour.com (BRASIL, 2011a), a partir do método de pesquisa voltado ao estudo da promoção de destinos turísticos via Web de Díaz Luque (2005), que engloba quatro aspectos: conteúdo informativo, capacidade de comercialização e distribuição, canais e recursos de comunicação interativos usados e oferta de versões do portal em idiomas estrangeiros.

O primeiro aspecto abordou a informação contida no portal (temas citados, dados de localização geográfica, clima, fuso horário, distribuição do conteúdo, dicas de viagens sobre vistos e passaportes, vacinação, informação sobre atrativos e passeios no destino, informações sobre aspectos culturais, econômicos, religiosos, políticos etc.). $\mathrm{O}$ segundo aspecto investigou a capacidade de comercialização e distribuição do portal para verificar se oferecia algum sistema de reserva online para facilitar o planejamento das viagens dos internautas.

O terceiro aspecto avaliou a interatividade, ao observar os canais e recursos utilizados para estabelecer a comunicação interativa entre a EMBRATUR e o turista em potencial, passando por canais de comunicação como telefone até recursos disponíveis online: e-mail, formulário de contato, redes sociais ("Twitter", "Facebook", "Foursquare"), sites de compartilhamento ("YouTube", "Flickr"), blog, estes últimos representantes da Web 2.0, que estimula a participação do internauta por meio da edição e publicação simplificada de material na internet (O'REILLY, 2005). Por fim, registrouse a existência de versões do portal em idiomas alternativos ao próprio da região, com o intuito de conhecer os principais públicos-alvo quando o assunto é atrair turistas internacionais ao país.

O artigo é composto por três partes teóricas: em um primeiro momento, enfatizase a relação entre turismo e TIC, em seguida, aborda-se o tema eMarketing de destinos turísticos e, por último, discute-se o eTourism no Brasil. Na sequência, são apresentadas a análise e as considerações finais da pesquisa.

\section{TURISMO ELETRÔNICO}

A incorporação crescente das TIC à atividade turística deu origem à expressão eTourism (Turismo eletrônico), proposta por Buhalis (2003), para se referir à 
digitalização de todos os processos e elementos da cadeia de valor do turismo como uma possibilidade de maximizar a eficiência e a eficácia das organizações. Além disso, as TIC podem melhorar as funções de vários negócios como eCommerce (Comércio eletrônico), eMarketing (Marketing eletrônico), eFinance (Finanças eletrônicas), ePlanning (Planejamento eletrônico) e eManagement (Gerência eletrônica). Observa-se que as TIC são fundamentais para o turismo por se tratar de uma atividade que requer a geração, coleta, processamento, implementação e comunicação dos dados e informações para realizar as diversas operações.

Por sua vez, os autores Cooper et al. (2007) argumentam que o rápido crescimento do volume de viajantes em 1990 e a demanda por produtos sofisticados, especializados e qualificados, também têm impulsionado a necessidade de adotar as TIC no turismo. Afinal, a internet oferece informações transparentes e facilmente comparáveis sobre destinos, pacotes de férias, passagens, hospedagem, gastronomia e serviços de lazer, assim como exibe a disponibilidade e o valor atualizado de tarifas.

Os consumidores utilizam cada vez mais sites comerciais e não comerciais da internet para planejamento, pesquisa, reserva, compra e acréscimo de seus produtos turísticos. Eles também podem obter confirmação imediata e rapidez nos documentos de viagem, possibilitando reservas de última hora. (COOPER et al., 2007, p. 683).

O incremento das TIC e, particularmente, da internet, gera o empoderamento do novo turista que se torna cada vez mais versado e capaz de avaliar de modo excepcional o dinheiro e o tempo investidos. Ele está menos interessado em acompanhar a multidão em pacotes de excursão, os quais estão perdendo participação no mercado em decorrência do avanço do modelo de turismo organizado independentemente, facilitado pela dinâmica de empacotamento, ou seja, a possibilidade da pessoa montar seu próprio pacote de viagem (BUHALIS; LAW, 2008).

Vale registrar que, com o passar dos anos, a rede se fortalece como mídia promotora de interação social apoiada por recursos da segunda geração da interface gráfica da internet, a World Wide Web. De acordo com O’Reilly (2005), a Web 2.0 valoriza a arquitetura de participação na rede com o objetivo de oferecer ricas experiências aos usuários, facilitando os processos de edição e publicação de conteúdo para ampliar a colaboração.

A Web 2.0 aparece como uma evolução natural do modelo de Web projetada por 
Tim Berners-Lee na década de 1990, a então Web 1.0, caracterizada por páginas com conteúdos estáticos e pela pouca interação com o usuário (O’REILLY, 2005). Portanto, a segunda geração da Web é estratégica para a difusão da atividade turística em nível mundial; especialmente com a chance do viajante divulgar positiva ou negativamente os produtos e serviços experimentados nos destinos por meio de redes sociais e recursos como o blog, no qual o usuário produz, edita e publica seu próprio conteúdo, mantendo um diálogo com seus leitores que participam enviando comentários.

Buhalis e Law (2008) admitem que grupos online, gradualmente, estão se consolidando como canal de influência na tomada de decisão referente ao turismo, já que os consumidores confiam mais em seus pares do que em mensagens de marketing. A emergência da Web 2.0 e, por conseguinte, do Travel 2.0 está associada diretamente ao conceito de rede social que é largamente aplicado à atividade turística na atualidade. Essa linha de pensamento vai ao encontro das ideias de Huertas (2008, p. 3, tradução nossa), ao defender que:

\footnotetext{
As opiniões e as experiências de outros consumidores são uma fonte muito valiosa de informação para os turistas em potencial, uma vez que ajudam a reduzir a sensação de risco e desconhecimento a respeito dos serviços turísticos [...]. As vivências e os relatos positivos de outros usuários, assim como o modo de descrição dessas experiências, com comentários emocionantes e fotografias, podem motivar e convencer muito mais que uma simples informação ou um folheto turístico.
}

Dito de outra maneira, a internet cada vez mais se destaca como mídia capaz de promover interação e até estreitar relacionamentos comerciais. Também como assinala O’Connor (2001), os turistas precisam obter informações antes de partir para uma viagem, logo, a divulgação de conteúdo qualificado é útil para planejarem e tomarem decisões. Todo o processo de busca por informação gira em torno da principal característica do produto turístico: a intangibilidade, que elimina qualquer possibilidade dos turistas saberem o que encontrarão na viagem programada, ou seja, é necessário que haja o deslocamento até o destino turístico para se consumir efetivamente o produto.

\section{MARKETING ELETRÔNICO DE DESTINOS TURÍSTICOS}

O eMarketing figura como um dos campos estimulados pelas práticas do eTourism (BUHALIS, 2003), sendo a adoção das TIC avaliada como uma vantagem 
competitiva para a promoção dos destinos turísticos. Para isso, é fundamental o planejamento estratégico na área de marketing turístico, entendido como o “[...] conjunto de técnicas aplicadas por empresas de turismo para a comercialização e distribuição de produtos e serviços para atender as necessidades dos diferentes grupos de consumidores e obter lucro.” (BALANZÁ; NADAL, 2003, p. 41).

No caso do eMarketing, a divulgação de informações aparece como um dos principais objetivos de Web sites elaborados para promover destinos turísticos, os quais devem oferecer conteúdos e recursos capazes de chamar a atenção de turistas potenciais. Por esta razão, deve-se analisar a existência de uma série de conteúdos, pois: "Estes conteúdos tratam de satisfazer as necessidades de informação dos turistas para que eles possam se deslocar e realizar diversas atividades no destino." (DIAZ LUQUE; GUEVARA; ANTON, 2006, p. 3).

De acordo com Díaz Luque (2005), as linhas turísticas ou os produtos turísticos líderes devem ser exibidos no Web site da destinação como elementos claros de atração para os segmentos de mercado selecionados. Assim, a presença do destino na internet deve estar integrada à estratégia de marketing em todos os aspectos, sendo um deles o produto. Para o autor, é necessário aumentar a conscientização sobre a promoção do produto turístico através da Web como estratégia de marketing definida, com foco nas áreas, linhas e produtos analisados como principais para atrair os turistas almejados. Além disso:

O marketing eletrônico deve funcionar em harmonia com as atividades tradicionais de marketing, de forma que a movimentação aconteça em ambas as direções, da Web para os folhetos ou para o telefone, do telefone para a Web, e assim por diante. (OMT, 2003, p. 36).

No cenário do marketing turístico, é fundamental a criação de uma marca forte capaz de divulgar positivamente a imagem do produto. Na concepção de Tsiotsou e Ratten (2010), a marca é uma estratégia usada para diferenciar produtos e empresas; além de atribuir valor econômico tanto para o consumidor quanto para o proprietário da marca. Um dos conceitos mais importantes relacionados à marca é a imagem de marca, que se refere ao valor adicional que uma marca confere a um produto e à adição de atributos da marca, como reputação, símbolos, associações e nomes.

Por meio do reconhecimento de uma marca, é possível estabelecer uma relação de fidelização com os clientes. Todavia, criar e manter o reconhecimento de uma marca 
é um desafio para os profissionais de marketing, pois precisam garantir que o produto ou a marca seja lembrado pelo consumidor como uma das opções disponíveis no mercado.

Assim, a imagem de um destino é um fator determinante do marketing turístico (TSIOTSOU, RATTEN, 2010), sendo a compreensão acerca da imagem de um destino necessária para todo plano de marketing de destino turístico, pois as estratégias empregadas praticamente definem a imagem pública que irá assumir:

\begin{abstract}
Os turistas formam uma imagem de um destino turístico após passarem por um processo que, de acordo com Gunn (1988), envolve os seguintes estágios: (1) acúmulo de imagens mentais do destino, formando então uma imagem orgânica; (2) modificação da imagem inicial depois de adquirir mais informações, formando então uma imagem induzida; (3) decisão de visitar o destino; (4) visita ao destino; (5) comentários sobre o destino; (6) retorno; e (7) modificação da imagem a partir da experiência no destino. (GUNN, 1988 apud COOPER et al., 2007, p. 657). ${ }^{2}$
\end{abstract}

Nota-se o quanto o planejamento de marketing de destinos é complexo, ao lidar não apenas com o inventário tangível dos atributos físicos (a geografia natural, o ambiente e as atrações construídas, a hotelaria e a estrutura de transporte), mas com fatores culturais e sociais intangíveis. Destaca-se que o setor público, em geral, tem atuado no marketing de destinos turísticos por meio das organizações nacionais de turismo, como acontece no Brasil com a EMBRATUR, com foco na divulgação internacional da imagem do país.

Buhalis (2000) reforça que além do vínculo governamental (local, regional ou nacional), organismos gestores de destinos têm poder político e legislativo, bem como os meios financeiros para gerir racionalmente os recursos para que todas as partes interessadas possam se beneficiar em longo prazo. Nesse contexto, o marketing deve ser utilizado como um mecanismo estratégico em coordenação com o planejamento e a gestão, e não se limitar a uma ferramenta de vendas.

É válido ressaltar que, como advertem Cooper et al. (2007), as organizações de marketing do setor público raramente fecham uma venda, pois agem como instrumentos para atrair o consumidor ao ponto de venda - empresa do setor privado. Por isso, tornase difícil avaliar a eficácia do marketing do destino. O ideal é que nos destinos sejam identificados os atributos de produto que terão apelo a diferentes segmentos de turistas,

\footnotetext{
${ }^{2}$ GUNN, C. Vacationscapes: Designing tourist regions. New York: Van Nostrand Reinhold, 1988.
} 
para garantir que a campanha promocional apresente uma mensagem coerente. Segundo os autores, existe, ainda, a necessidade de produzir uma identidade distinta ou marca que forme a base para o posicionamento de um destino detentor de uma personalidade, a qual o diferenciará de seus concorrentes.

$\mathrm{Na}$ concepção de Gretzel et al. (2006), o turismo tem mudado de forma estrutural, sendo que novos avanços em tecnologia e na sociedade são esperados para redefinir continuamente o que o turismo será ou pode ser. Um passo essencial no processo de busca sobre o futuro do turismo, em geral, e do marketing de destino, em particular, envolve localizar os problemas que provavelmente terão impactos significativos no futuro do turismo. Ademais, os autores alertam que tendências com altos impactos potenciais sobre o turismo muitas vezes se relacionam a mudanças nos mercados de consumo, assim como no ambiente global organizacional. Por sua vez, tais mudanças forçam as organizações gestoras de destinos a pensar de modo diferente e a adotar novas abordagens para lidar com seus clientes, nesse caso, os novos turistas que participam ativamente de grupos online, segundo Buhalis e Law (2008).

\section{ETOURISM DA DESTINAÇÃO BRASIL}

Com a adoção das TIC e da rede internet, o setor de turismo e das viagens passou a conquistar clientes e a se destacar no comércio eletrônico global, e em pouco tempo tornou-se a maior categoria individual de produtos vendidos pela internet nos Estados Unidos (OMT, 2003). Trata-se de uma tendência que se dissemina pelo mundo afora e adquire força em território brasileiro.

A busca por informações sobre viagens e turismo por meio da conexão à internet, usando dispositivos de bases físicas ou móveis, é uma realidade, e o mercado tende a se expandir ainda mais. No ano de 2012, 60\% das reservas de viagens serão realizadas online, de acordo com o diretor de vendas da empresa Google Inc. no Brasil, Huettner, considerando também que as viagens contratadas por telefones celulares têm taxas de crescimento de três dígitos, depois de ter crescido $276 \%$ no Brasil, no período de 2009 a 2010 (HUETTNER, 2011).

Por sua vez, uma pesquisa da EMBRATUR (BRASIL, 2009), organismo vinculado ao Ministério do Turismo e responsável pela promoção turística internacional 
do país, revela que 63\% dos turistas estrangeiros que visitaram o Brasil em 2009 buscaram informações via internet antes da viagem, e 13\% acessaram o portal oficial do turismo brasileiro (www.braziltour.com). Consequentemente, para o país que sediará importantes eventos esportivos internacionais, como a Copa do Mundo de Futebol de 2014 e os Jogos Olímpicos de 2016, é de vital importância incentivar a promoção turística com o auxílio das TIC.

Inclusive há uma preocupação por parte da EMBRATUR com a grande conectividade que caracterizará os megaeventos esportivos no Brasil, dada a presença marcante da internet como uma mídia de comunicação e promoção até agora não vista. Nesse contexto, em 2009 foi lançado o "Plano Aquarela 2020. Marketing Turístico Internacional do Brasil", com algumas diretrizes acerca da promoção de destinos nacionais por meio da internet e outros dispositivos móveis de conexão (BRASIL, 2009).

Ademais, o cuidado com o processo de elaboração de conteúdo para um Web site com enfoque em turismo tende a aumentar mediante a observação do diretor de vendas do Google no Brasil, Huettner (2011), de que "[...] as pessoas passam 5\% do tempo realizando buscas sobre viagens e 95\% do tempo consultando o Web site indicado", sendo que os usuários se preocupam majoritariamente com preço, conteúdo e interatividade. Ressalva-se que o item preço recebe atenção especial no eTourism, tanto que muitas organizações usam as TIC para comunicar ao consumidor tarifas exclusivas via Web, repassando os descontos proporcionados pela ausência de pagamento de comissões e taxas de distribuição da cadeia de valor tradicional (BUHALIS; LAW, 2008).

Na rede internet, é comum encontrar Web sites que fornecem informações sobre destinos, como as páginas oficiais de promoção turística de cidades e países, quando predomina a intenção de divulgar informações sobre um local e sua cultura, assim como indicar a melhor forma de aproveitar a viagem. A ideia não é proporcionar um tipo de experiência de viagem sem deslocamentos, mas principalmente informar. Ao reconhecer a função primordial da internet como promotora de destinos turísticos, apresenta-se, a seguir, a análise do portal www.braziltour.com com a proposta de estudar as estratégias de eMarketing do país Brasil como destino turístico internacional. 


\section{ANÁLISE DO PORTAL BRASILEIRO DE TURISMO}

A análise do Web site oficial www.braziltour.com (BRASIL, 2011a) se baseou no método de pesquisa aplicado ao estudo da promoção de destinos turísticos via Web, conforme mencionado anteriormente. Contudo, torna-se necessário esclarecer que o estudo não teve como foco a análise de imagens (fotos e vídeos) em profundidade, partindo-se do princípio de que o conjunto de material publicado contribui para a formação da imagem da marca Brasil.

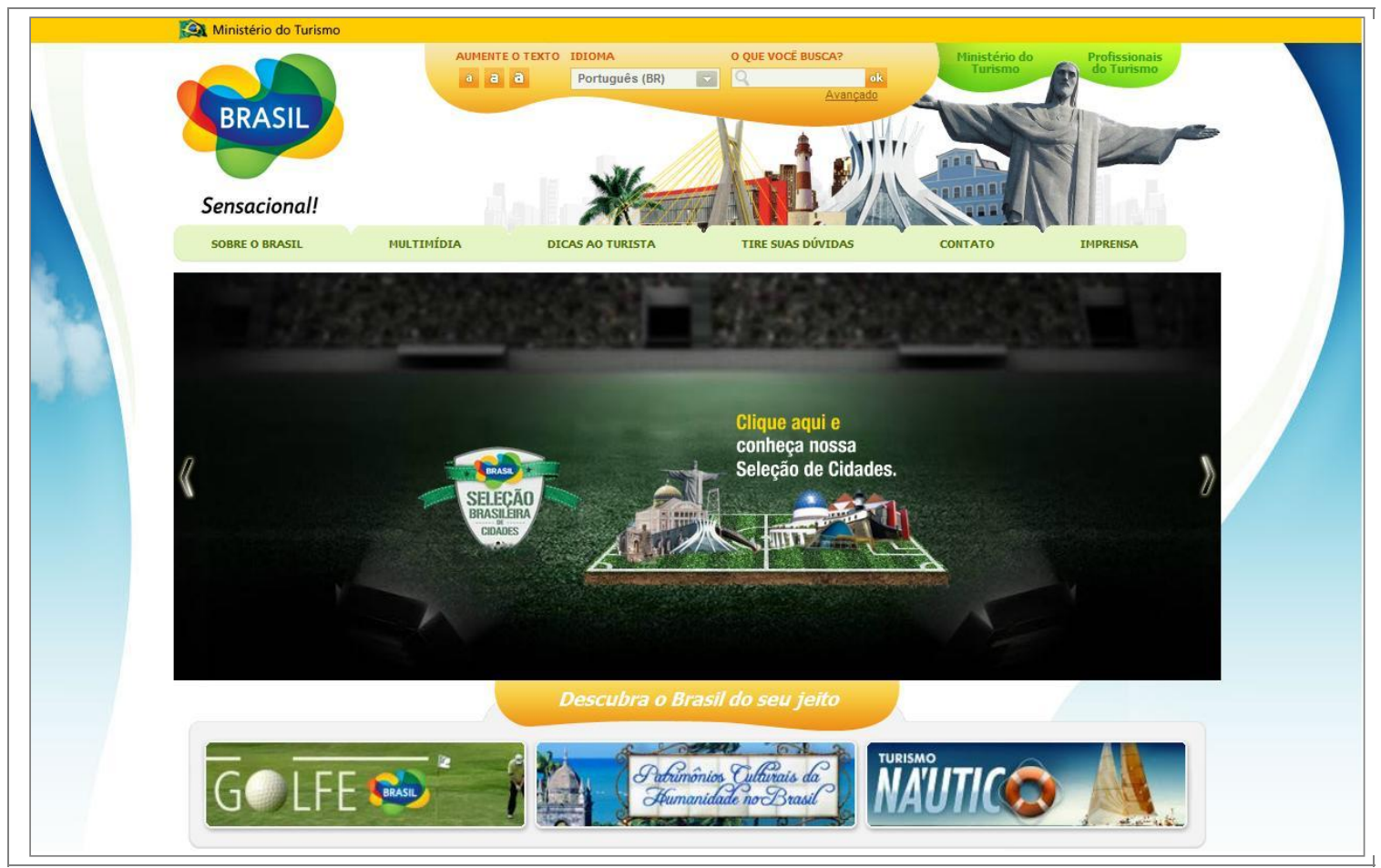

FIGURA 1 - HOME PAGE DO PORTAL "BRAZIL TOUR"

FONTE: WEB SITE OFICIAL “BRAZIL TOUR” (BRASIL, 2011a).

Em um primeiro momento, realizou-se a observação geral do Web site visando avaliar o conteúdo informativo disponibilizado. De imediato, o evento Copa do Mundo de 2014 é explorado como atrativo central do destino Brasil, o qual deve liderar a campanha promocional da marca do país de agora em diante. Abaixo, aparecem três banners que se referem ao esporte golfe, a patrimônios culturais da humanidade existentes no país e a turismo náutico, respectivamente, como uma maneira de apresentar esses temas como possibilidades de atrações ao turista estrangeiro. 
$\mathrm{Na}$ parte superior do portal, aparece о тепи principal com destaque para os itens: "Sobre o Brasil", "Multimídia", "Dicas ao Turista", "Tire suas Dúvidas", "Contato" e "Imprensa". Logo no link "Sobre o Brasil", há uma variedade de informações a respeito do país, com dados de ordem geográfica, extensão territorial, limites fronteiriços, e inclusive comentários sobre o idioma, aspectos da formação cultural do país, marcado pela forte miscigenação, até uma breve apresentação sobre o regime democrático que vigora no país.

$\mathrm{Na}$ sequência, exibe-se uma listagem de informações úteis que abrangem assuntos como: vistos e passaportes, corrente elétrica, aluguel de automóvel, táxis, gorjetas, moeda, comunicações, língua, clima e fusos horários. São dicas importantes, mas que deixam essa página carregada de conteúdo, o que pode cansar de início o turista em potencial.

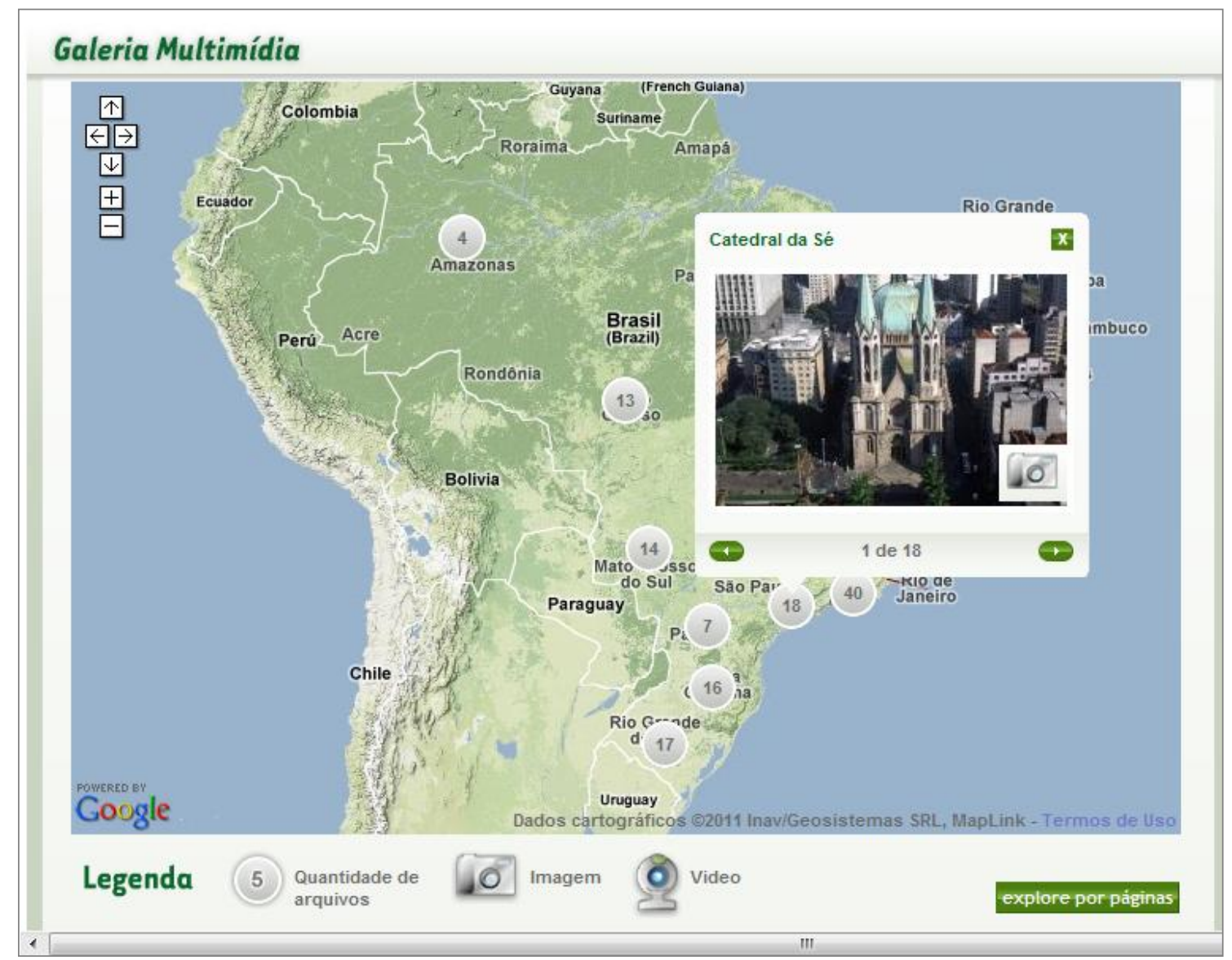

FIGURA 2 - PÁGINA "MULTIMÍDIA"

FONTE: WEB SITE OFICIAL “BRAZIL TOUR” (BRASIL, 2011a). 
No link denominado "Multimídia", é possível acessar a galeria multimídia com uma série de imagens retratando os vários destinos turísticos espalhados pelo país e cobrindo todas as cinco regiões: Norte, Nordeste, Centro-Oeste, Sudeste e Sul. Ao clicar em cada numeração no mapa interativo, a pessoa pode visualizar fotos e vídeos relacionados aos lugares, sejam cidades ou pontos turísticos famosos de cada região.

No item "Dica ao turista", são indicadas informações específicas sobre aeroportos, moeda, clima, passaporte e visto, consulados e embaixadas, e vacinação. Trata-se de assuntos de interesse do turista em potencial ao indicar, por exemplo, endereços de casas de câmbio, de consulados e embaixadas. São dicas imprescindíveis para guiar o viajante, lembrando sempre que apesar de toda informação, nunca se pode ter certeza do que se encontrará e experimentará no destino, dada a característica de intangibilidade do produto turístico, como enfatizado por O’Connor (2001). Porém, o problema é que algumas informações já tinham sido abordadas no primeiro link intitulado "Sobre o Brasil". Algo que reflete em redundância informacional.

Com relação aos canais e recursos de comunicação interativos oferecidos, o link "Tire suas dúvidas" funciona como Frequently Asked Question (FAQ). Nesse caso, o ideal seria que o Portal adotasse a nomenclatura em inglês ou a sigla FAQ conhecida internacionalmente para facilitar a compreensão do turista estrangeiro. No tópico “Contato", há um formulário online para o viajante se comunicar diretamente com a EMBRATUR, assim como uma listagem contendo os endereços físicos, eletrônicos e números de telefones dos escritórios no país, cuja sede localiza-se em Brasília, e no exterior (Portugal, Japão, Itália, França, Estados Unidos da América, Espanha, América do Sul, Alemanha e Reino Unido).

Ao clicar no último link do menu nomeado "Imprensa", o turista é redirecionado para o Web site Brasil Network - Programa de Relacionamento do Turismo Brasileiro (BRASIL, 2011b). Nessa página, são publicados resultados sobre o turismo no país nos últimos anos, estudos e pesquisas sobre demanda turística, notícias e releases sobre a EMBRATUR, fotos e agenda de eventos. 


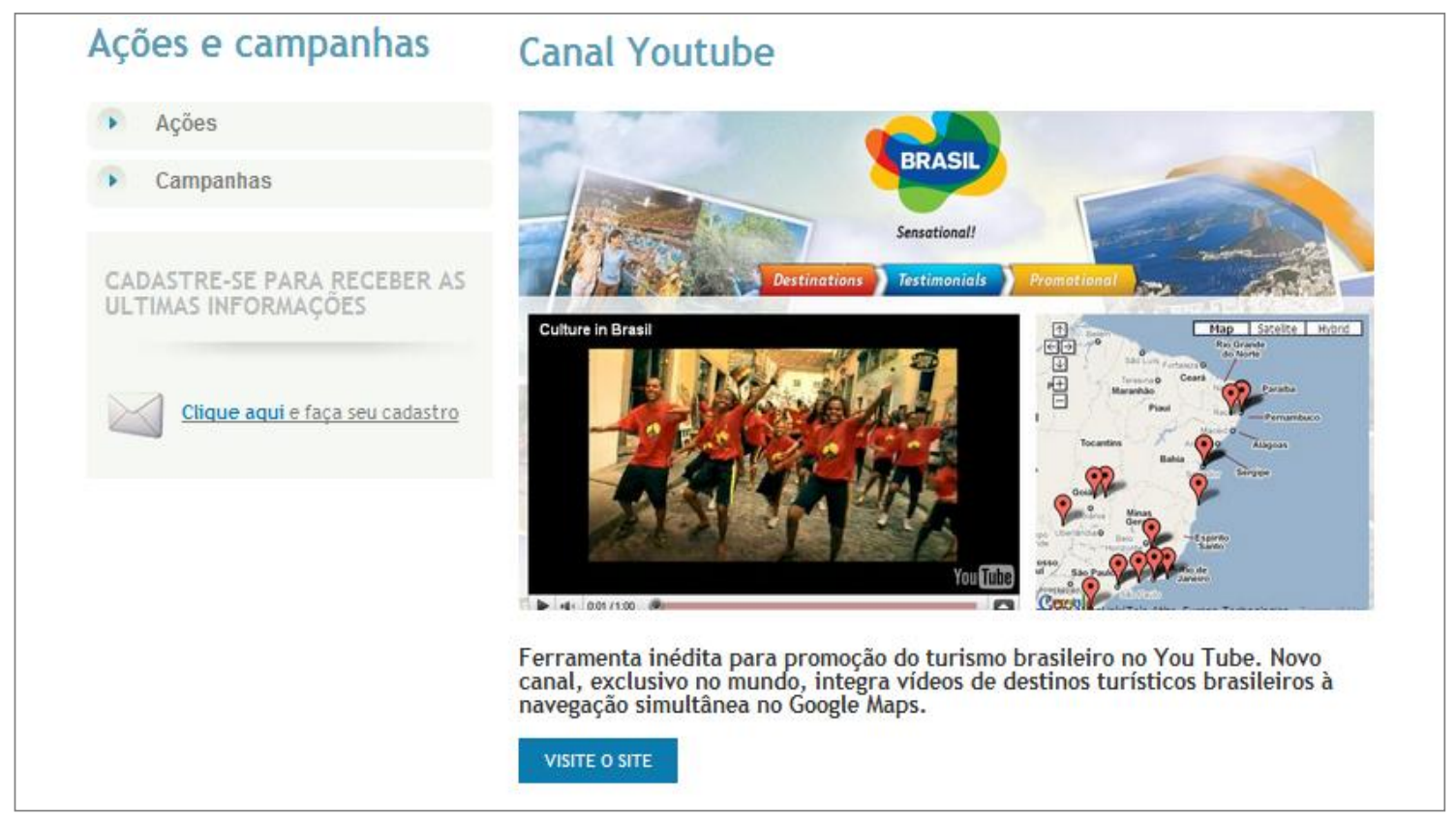

FIGURA 3 - PÁGINA “AÇÕES DA EMBRATUR”

FONTE: WEB SITE BRASIL NETWORK (BRASIL, 2011b).

Ocorre ainda a divulgação de ações e campanhas promocionais a partir de canais de comunicação interativos da internet, como os sites de compartilhamento de vídeo "YouTube" e de fotos "Flickr", as redes sociais "Twitter" e "Foursquare", e o blog da EMBRATUR, todos representantes da chamada Web 2.0 (O'REILLY, 2005; HUERTAS, 2008). Também é relevante destacar que existe a divulgação de mensagens via redes sociais em vários idiomas para estabelecer uma interação com o público estrangeiro.

No que se refere à identificação de atributos de produtos capazes de atrair diferentes segmentos de turistas e que, portanto, juntos ajudam a compor a marca do destino turístico (COOPER et al. 2007; TSIOTSOU, RATTEN, 2010), são anunciados na parte inferior da primeira página do portal "Brazil tour" os seguintes segmentos: "Sol e Praia", "Esportes", "Ecoturismo", "Cultura" e "Negócios e eventos" (Figura 4). Tais segmentos foram selecionados para representar a imagem do Brasil no exterior, posicionando-o como um destino detentor de uma identidade própria, personalizada, a qual o diferenciaria de seus concorrentes. 


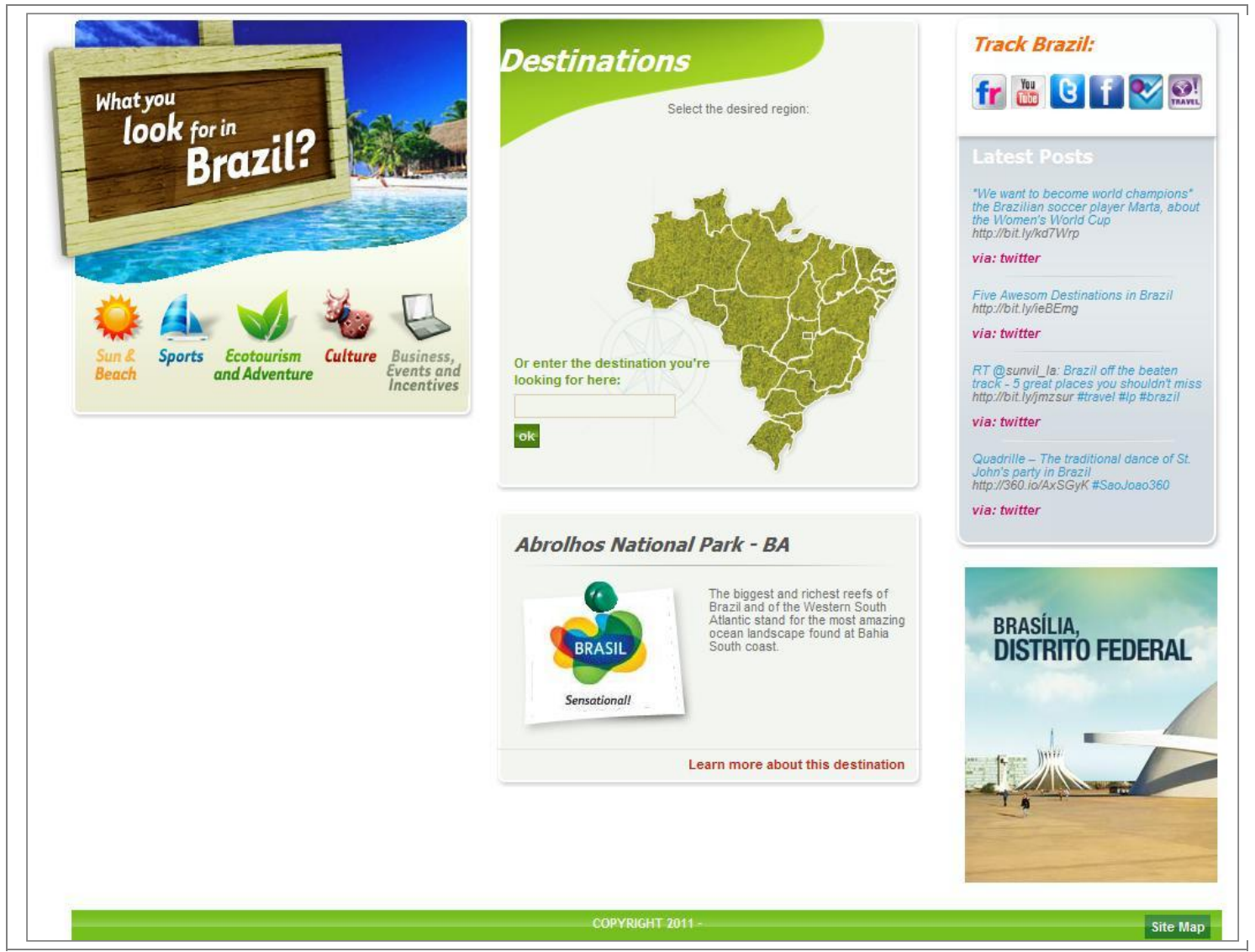

FIGURA 4 - PARTE INFERIOR DA HOME PAGE DO PORTAL

FONTE: WEB SITE OFICIAL “BRAZIL TOUR” (BRASIL, 2011a).

A proposta de realçar as linhas ou os produtos turísticos no Web site da destinação como elementos claros de atração para os segmentos de mercado selecionados atende em parte os preceitos sugeridos por Díaz Luque (2005), uma vez que a distribuição espacial dessa informação avaliada como importante não parece ser a mais adequada. A informação sobre os cinco segmentos está localizada no canto inferior e à esquerda da página principal, sendo necessário rolar a barra lateral para vê-la, como ilustrado na Figura 4.

É válido ressaltar que, além do artifício de enfatizar as belezas das paisagens naturais do país, evidente nos segmentos "Sol e Praia", "Esportes", "Ecoturismo", existe um trabalho de promoção do destino turístico Brasil que envolve aspectos intangíveis como a tradição cultural. Há também uma aposta no posicionamento do Brasil como opção para sediar diversos eventos e reuniões de negócios; uma tendência que se consolidará por completo mediante a realização dos megaeventos esportivos desta década. 
Com relação à capacidade de comercialização e distribuição por meio do portal "Brazil tour", constata-se, como registrado por Cooper et al. (2007), o papel inexpressivo dos organismos vinculados ao setor público no âmbito comercial, como no caso específico da EMBRATUR, cuja estrutura não permite a comercialização de produtos e serviços turísticos brasileiros.

No que diz respeito ao potencial de comunicação para alcançar o público internacional, objetivo primeiro do Portal Brasileiro de Turismo, o marketing eletrônico é trabalhado no sentido de mobilizar a atenção de turistas que dominam os seguintes idiomas: inglês (com versões diferenciadas de sites para o inglês padrão e o praticado no Reino Unido); alemão; espanhol; francês; e italiano. Vale mencionar que com relação ao idioma português, há versões distintas de sites para o português corrente no Brasil e o falado em Portugal. Nesse contexto, deve-se estabelecer uma ligação entre as versões do site em línguas estrangeiras e os públicos de interesse, de acordo com os segmentos turísticos identificados como componentes da imagem da marca do país.

\section{CONSIDERAÇÕES FINAIS}

A pesquisa sobre as estratégias de Marketing eletrônico do Brasil como destino turístico internacional, mediante a análise do portal "Brazil tour", mostrou que existe um planejamento de marketing por parte da EMBRATUR quando o assunto é divulgação do país com o suporte das TIC e da internet. O conteúdo informativo do Web site é relevante e atraente para os públicos-alvo definidos previamente, a partir do enfoque em segmentos turísticos específicos: "Sol e Praia", "Esportes", "Ecoturismo", "Cultura" e "Negócios e eventos".

Como esses cinco segmentos são anunciados como os elementos-chave de promoção turística no Brasil, seria ideal que recebessem um destaque maior na distribuição espacial da primeira página do portal ou que aparecessem indicados como links no mеnu principal. Desse modo, os temas identificados como componentes da marca do país seriam visualizados de imediato quando acessados pelos turistas estrangeiros, sem necessitar rolar a barra para encontrá-los na parte inferior da página do Web site. 
O Portal Brasileiro de Turismo fornece dados significativos que ajudam a satisfazer a curiosidade inicial do novo turista, entretanto, há uma redundância informacional, quando o mesmo tipo de assunto ou dica aparece em diversas páginas internas. No quesito capacidade de comercialização e distribuição, percebe-se a limitação característica de um organismo vinculado ao setor público, que não tem permissão para atuar diretamente com esse foco.

Finalmente, os responsáveis pelo Marketing eletrônico da EMBRATUR estão dispostos a interagir com os turistas internacionais, não somente por meio da disponibilização do Web site em línguas estrangeiras, mas pela adoção de uma variedade de canais de comunicação interativos via internet, entre os quais, "Facebook", "Twitter", "Flickr", "YouTube" e "Foursquare". Medida que vai ao encontro da preocupação da EMBRATUR com o elevado grau de conectividade que caracterizará os megaeventos esportivos de 2014 e 2016 em território brasileiro.

Nessa perspectiva, a proposta de mobilizar os turistas potenciais e os chamados novos turistas, mais sofisticados e exigentes, já está em processo, pois é obrigatório estar onde as pessoas de fato hoje buscam informação, como, por exemplo, as redes sociais e demais recursos de compartilhamento da Web 2.0. Todavia, não é suficiente apenas criar canais de interação com os turistas; torna-se essencial compreender as demandas do novo viajante independente, que não se limita a buscas em Web sites oficiais, mas que prefere confiar no comentário publicado até mesmo por uma pessoa desconhecida em alguma rede social. O profissional de marketing deve acompanhar a mudança de comportamento do turista contemporâneo, ter dedicação e, sobretudo, dar respostas rápidas em uma época de conexão global.

\section{REFERÊNCIAS}

BALANZÁ, M. I.; NADAL, M. C. Marketing e comercialização de produtos turísticos. São Paulo: Pioneira Thomson Learning, 2003.

BRASIL. Ministério do Turismo. Plano Aquarela 2020. Marketing Turístico Internacional do Brasil. Brasília, DF, 2009.

BRASIL. Ministério do Turismo. Portal Brasileiro de Turismo. Brasília, DF, 2011a. Disponível em: <www.braziltour.com>. Acesso em: 10/07/2011. 
BRASIL. Ministério do Turismo. Brasil Network - Programa de Relacionamento do Turismo Brasileiro. Brasília, DF, 2011b. Disponível em: <http://www.brasilnetwork.tur.br/>. Acesso em: 10/07/2011.

BUHALIS, D. eTourism: informations technologies for strategic tourism management. London: Prentice Hall, 2003.

Marketing the competitive destination of the future. Tourism Management, V. 21(1), p. 97-116, 2000.

BUHALIS, D.; LAW, B. Progress in information technology and tourism management: 20 years on and 10 years after the Internet - The state of eTourism research. Tourism Management, V. 29 (4), p. 609-623, 2008.

COOPER, C.; FLETCHER, J.; FYALL, A.; GILBERT, D.; WANHILL, S. Turismo: princípios e prática. Porto Alegre: Bookman, 2007.

DIAZ LUQUE, P. Metodología para la presencia de las zonas turísticas españolas en internet. Las organizaciones de destinos turísticos. $358 \mathrm{f}$. Tese (Doutorado em Política Econômica) - Departamento de Economia Aplicada da Universidad de Málaga, Málaga, 2005.

DIAZ LUQUE, P.; GUEVARA, A.; ANTON, S. La presencia en Internet de los municipios turísticos de sol y playa. Mediterráneo y Canarias. In: CONGRESO $\begin{array}{llllll}\text { TURISMO } & Y & \text { TECNOLOGÍAS DE LA INFORMACIÓN } & Y & \text { LAS }\end{array}$ COMUNICACIONES, 6., 2006. Anais... Málaga, UMA, 2006, p. 1-23.

GRETZEL, U.; FESENMAIER, D. R.; FORMICA, S.; O'LEARY, J. T. Searching for the Future: Challenges Faced by Destination Marketing Organizations. Journal of Travel Research, V. 45 (2), p. 116-126, 2006.

HUERTAS, A. Aplicación de la Web 2.0 a los destinos turísticos. Implantación y diferencias. In: CONGRESO TURISMO Y TECNOLOGÍAS DE LA INFORMACIÓN Y LAS COMUNICACIONES, 8., 2008. Anais... Málaga, UMA, 2008, p. 1-16.

HUETTNER, A. Canais de Distribuição e Segmentação de Mercado. In: FÓRUM PANROTAS, 9., 2011. São Paulo: Fecomercio, 2011.

O'CONNOR, P. Distribuição da Informação Eletrônica em Turismo e Hotelaria. Porto Alegre: Bookman, 2001.

O'REILLY, T. What is Web 2.0: design patterns and business models for the next generation of software? In: O’REILLY MEDIA. O'Reilly. Sebastopol, 2005. Disponível em: <http://www.oreillynet.com/pub/a/oreilly/tim/news/2005/09/30/whatis-web-20.html >. Acesso em: 20/04/2007. 
ORGANIZAÇÃO MUNDIAL DE TURISMO. E-Business para turismo. Porto Alegre: Bookman, 2003.

TSIOTSOU, R.; RATTEN, V. Future research directions in tourism marketing. Marketing Intelligence \& Planning, V. 28 (4), p. 533-544, 2010.

Recebido em: 22-12-2011.

Aprovado em: 22-01-2012. 